\title{
Development of Innovative Solutions for Intelligent Inspection of Products of Additive Manufacturing for Navy Supply
}

\author{
Alexander KRAVCOV ${ }^{1}$, Pavel SVOBODA ${ }^{1}$, Jiří ŠTOLLER ${ }^{2}, Z_{\text {Zdeněk POKORNÝ }}^{2}$, Jerzy \\ MALACHOWSKI ${ }^{3}$, Pawel PLATEK ${ }^{3}$, Pawel BARANOWSKI ${ }^{3}$, Leopold KRUSZKA ${ }^{3}$, Aidas \\ VASILIS-VASILIAUSKAS ${ }^{4}$
}

${ }^{1}$ Czech Technical University in Prague, Faculty of Civil Engineering, Thákurova 7/2077, Prague 6 - Dejvice, 166 29, Czech Republic

${ }^{2}$ University of Defence, Faculty of Military Technology, Kounicova 65, 66210 Brno, Czech Republic

Matachowski Jerzy

${ }^{3}$ Military University of Technology, 2 Gen. Witolda Urbanowicza St., 00908 Warsaw, Poland

${ }^{4}$ General Jonas Žemaitis Miltitary Academy of Lithuania, Silo str. 5A, LT-10322 Vilnius

E-mail: ${ }^{1}$ alexandr.kravcov@fsv.cvut.cz

\begin{abstract}
Using of 3D printed spare parts for Navy supply supported by mentioned inspection meets the requirement for enhancing the logistic performance by provide to military end-users possibilities to produce spare parts using additive manufacturing solutions, particularly in the context of overseas operations, that can be easily presented with several examples. But with application of additive manufacturing in naval operations to product different objects in a variety of materials in an open water environment, we need to start with development of innovative solutions for intelligent inspection of products of selective laser melting from metallic powders is a topic of great importance in nowadays if we talk about real strategies in logistic support including overseas naval outposts support equipment and the reverse engineering of obsolescent parts such as many of those that could be found on the perspective sea platforms with particular focus on maritime littoral and high sea areas - demonstrate advantages of additive manufacturing.
\end{abstract}

KEY WORDS: metallic powders, additive manufacturing, Nondestructive examination, laser ultrasonic, ultrasonic structuroscopy, navy supply

\section{Introduction}

Using of 3D printed spare parts for Navy supply supported by mentioned inspection meets the requirement for enhancing the logistic performance by provide to military end-users possibilities to produce spare parts using additive manufacturing solutions, particularly in the context of overseas operations, that can be easily presented with several examples.

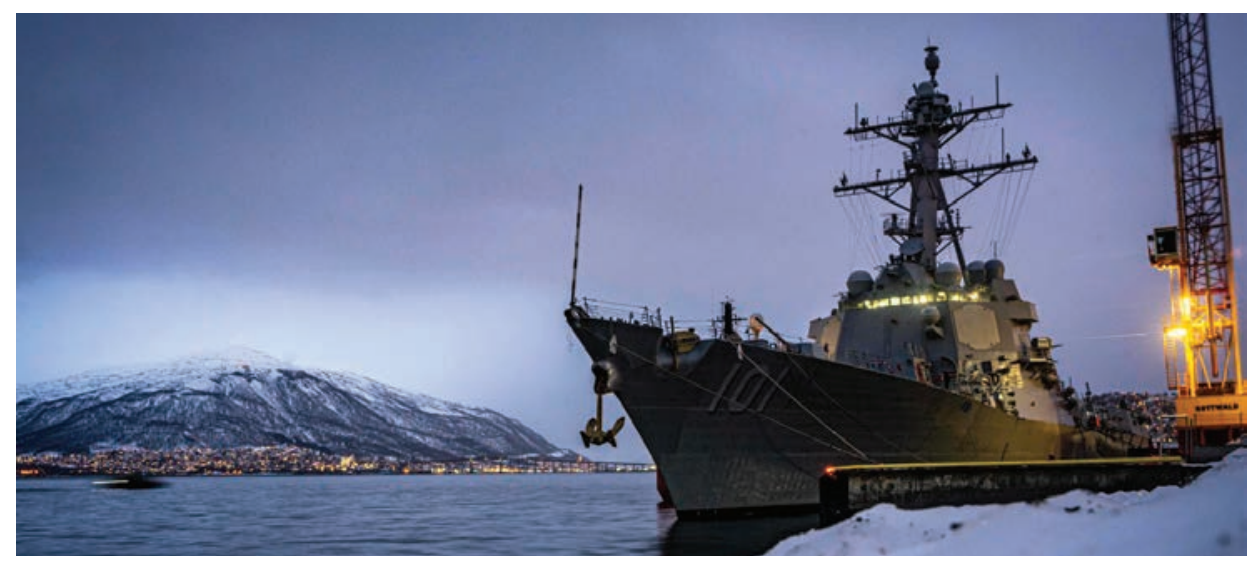

Fig. 1. USS Gridley (DDG-101) is moored pierside in Tromso, Norway, during a brief stop for fuel on Nov. 23, 2019 [1].

\footnotetext{
${ }^{1}$ Corresponding author.
}

E-mail address: alexandr.kravcov@fsv.cvut.cz 
The US Navy's Vice Admiral Philip Cullom, who is charged with the Navy's "Print the Fleet" additive manufacturing initiative, has stressed that the Navy's logistical supply chains are vulnerable and costly, and that additive manufacturing can offset some of that cost, particularly in austere times.

"When advanced manufacturing and 3D printing become widely available, we envision a global network of advanced fabrication shops supported by sailors with the skill sets and training to identify problems and build and make products," said Vice Admiral Philip Cullom, deputy chief of naval operations for fleet readiness and logistics. These advances will give the DoD increased capability to maintain, if not advance, our military dominance in the world - particularly in the low-intensity, long-duration combat of the "It is my strong belief that 3D printing and advanced manufacturing are breakthrough technologies for our maintenance and logistics functions in the future." - Vice Adm. Phillip Cullom Chief of Fleet Readiness \& Logistics, lead coordinator on the Navy's additive manufacturing efforts, explains for those new to 3D printing why the Navy is interested in this technology, and what it is already contributing [2].

The US Navy, for example, has conducted a Print the Fleet experiment which just in vary begging has produced about 20 applications for tooling, molding, repairs, prosthesis, cranial implants, and custom parts both on land and at sea. Print the Fleet experiment has began out as the Chief of Naval Operations Rapid Innovation Cell (CRIC), designs are shared via the Navy Additive Manufacturing Technology Interchange (NAMTI) [3]. The US Navy is taking additive manufacturing capabilities afloat by printing replacement oil reservoir caps on board ships via Print the Fleet. The Naval Undersea Warfare Center-Keyport uses additive manufacturing to create a supply of replacement parts to keep the fleet ready.

Norfolk Naval Shipyard's Rapid Prototype Lab is saving the Navy thousands of dollars on the Gerald R. Ford class of aircraft carriers. Instead of traditional wood or metal mockups of ship alterations, which help prevent expensive rework, the lab prints much cheaper plastic polymer models in hours, rather than days or weeks [4].

These and similar examples - including overseas naval outposts support equipment and the reverse engineering of obsolescent parts such as many of those that could be found on the perspective sea platforms with particular focus on maritime littoral and high sea areas - demonstrate the following advantages of additive manufacturing.

These and similar examples shows great importance of artefacts produced thanks to extensive research into additive manufacturing processes that have begun in the late 1980s. Most of the processes using in advanced manufacturing in maritime littoral and high sea areas are commercially available today [5,6]. Selective Laser Melting (SLM) allows components to be produced by localized melting of successive layers of metal powder [7]. As opposed to conventional manufacturing technologies, this method enables the fabrication of geometrically complex components [8] and has enormous commercial potential. However, the further development of additive manufacturing technologies (AMT) is partially hampered by a lack of in-process monitoring systems to control the temperature and geometry of the melt pool with high accuracy, as well as to monitor temperature gradients across the build area and detect defects directly during the SLM process.

The only standard available now for non-destructive testing in additive manufacturing [9] is very convoluted; moreover, it applies only to the final products and does not apply to in-process non-destructive evaluation to allow for early detection of flaws/defects. The standard [10] is to be revised in accordance with the Additive Manufacturing Standards Structure that was jointly approved by ISO Technical Committee 261 on additive manufacturing (ISO TC261) and STM International's committee on additive manufacturing technologies (ASTM F42). According to some researchers [6-16], there are over 50 different process input variables in selective laser melting, which affect the quality of the final product. The most common defects encountered in final products are pores that are situated in the bulk of the fused material either in between layers or within the layer, microcracks, laminations, residual stresses, distinctly different grain structures compared to the bulk of the material, etc. It is very important to ensure the early detection of these defects directly during the manufacturing process.

\section{Non-destructive Testing}

Therefore, the development and improvement of non-destructive evaluation methods for on-line monitoring of laser selective melting processes $[17,18]$ is an argent issue. Thermographic and visual monitoring methods are most commonly used today for non-destructive inspection of components during the build process. A large number of publications [19-38] indicate that these kinds of diagnostic inspection have advanced by leaps and bounds in recent years.

Most of these publications discuss the monitoring of electromagnetic radiation generated by the melt pool. High-speed cameras are used to monitor the size of the melt pool; pyrometers or thermal imagers based on photodiodes are used to measure the temperature of the melt pool or temperature gradients across the whole build area. Thermally stabilized high-speed cameras with appropriate spectral filters and a noise reduction system record, as a rule, the optical beam energy reflected from the melt pool area. This enables not only the visualization of the melt pool area, but 
also the evaluation of the energy contribution to the heating area. Temperature monitoring systems are also equipped with two pyrometers, one operating in the infrared (IR) range and the other, in the visible range. The IR pyrometer/ imager monitors the surface temperature of the object; the pyrometer operating in the range 400 to 600 nm signalizes process failures and surface layer evaporation [40-42].

These systems with high-speed IR cameras, coupled with high-speed image processing at a sampling frequency of $10 \mathrm{kHz}$ to $20 \mathrm{kHz}$, have shown great potential as a means to control the whole build, with melt pool areas, powder, and pores being roughly distinguished. However, the pyrometric techniques have a number of disadvantages. Thus, the actual resolution of these systems is of the order of $1 \mathrm{~mm}$ (not $40 \mu \mathrm{m}$ as per specifications), which is not enough to control the selective laser melting process; the measurement error of emissivity, which is a key parameter determining the true temperature of metal, is more than 5\%. Usually, only relative temperature readings could be recorded without accurate emissivity values. Also, there are no analytical models correctly describing the melt pool dynamics in a multilayer structure and heat flows arising due to material discontinuities. Numerical simulation cannot be carried out without this basis.

In this connection, other methods for controlling the selective laser melting process have been developed in the last five years, including X-ray tomography used for localizing cracks and pores [43] and neutron diffraction $[44,45]$ for evaluation of residual stresses. However, these methods have not come into widespread use because of considerable technical difficulties.

In [46-48], it is discussed whether acoustic emission can be used to detect cracks directly during the manufacturing of the component. In this case, a system of acoustic piezoelectric sensors is placed on the outer side of the platform and ultrasonic signals reflected by cracks are recorded. However, given multilayer materials, it is practically impossible to localize cracks and determine their geometry using these signals.

In $[49,50]$, it is proposed that ultrasonic echoscopy employing a $10 \mathrm{MHz}$ piezoelectric transducer glued to the back of the platform should be used to monitor the process of layer build-up, the condition of interfaces between the layers, and the formation of microcracks and pores. It is shown in $[49,50]$ that it is theoretically possible to monitor the dynamics of layers growth by means of ultrasonic echoscopy; pores about $1 \mathrm{~mm}$ in diameter were detected only on model samples, though.

\section{Non-contact Ultrasonic Methods}

Non-contact ultrasonic methods have a significant advantage over the conventional acoustic methods. This research area is addressed in [51-56], with special attention paid to laser excitation of acoustic signals. In this case, ultrasonic pulses are excited as a result of the absorption of pulsed laser radiation by the near-surface layer of the product being fabricated. The subsequent expansion of the heated region leads to the generation of elastic waves. As shown in research [57-58] by Mirzade, F.Kh., from Russian Academy of Sciences, Institute of Laser and Information Technologies, a pulse-periodic Q-switched laser emitting $10 \mathrm{~ns}$ pulses with $100 \mu \mathrm{J}$ pulse energy is an effective means to produce signals with pressure amplitude of up to $0.1 \mathrm{MPa}$ and duration of about $70 \mathrm{~ns}$. The amplitude of excited pressure pulses scattered by heterogeneities in the component being printed is large enough for the non-contact method based on the principles of laser interferometry to be used to monitor surface oscillations. In [56], it is shown that it is theoretically possible to use this non-destructive testing method in additive manufacturing; experiments were performed only on model samples, though. Mathematical modeling of thermal behavior for additive manufacturing with metal powder injection is developed in $[57,58]$.

Many scientific institutions are dealing with thermal imaging in the 3D printing: the Singapore Center for 3D Printing (School of Mechanical Engineering and Aerospace, Nanyang Technological University, Singapore), Department of Mechanical Engineering, Materials and Manufacturing Engineering, University of Nottingham, University Park, Nottingham NG72RD, United Kingdom, Fraunhofer Institute for Nondestructive Testing IZFP (Saarbrücken, Germany); Some groups are focused on the use of non-contact laser ultrasonics specifically for composite materials (Czech Technical University in Prague). The authors of this research worked with technology of contact laser ultrasonic flaw detectors with the unique resolution up to 50 microns [58].

Finite element analyses (FEA) can be effectively implemented to investigate various structures manufactured using additive technologies under different loading conditions. [60-64]. However, to consider the obtained outcomes as effective and close to the real-world results, a correct finite element (FE) model needs to be developed and its efficiency depends on many factors, especially the knowledge of material data [65-67]. In the project it is planned to: manufacture a selected product using the SLM with evaluated process parameters, experimentally test the product under the conditions reflecting real-world conditions and compare it with a standard product. Implementing numerical methods to the project will give the possibility to analyze the product using different material obtained through experimental acquisition of powder (material) data made using various process parameters. The multi-conditional FEA will be conducted to give the information about product properties and possible modifications. Based on the 
experimental and FEA results limits and strength of these solutions will be outlined (SWOT analysis). Application of optimization procedure is also planned to define the optimal geometrical parameters of the final product. The authors recently have carried out a series of studies aimed at testing and simulation of various structures manufactures using additive technologies [60, 61, 68-72].

The authors of this research worked with technology of contact laser ultrasonic flaw detectors with the unique resolution up to 50 microns, in [58] you can see laser ultrasonic structuroscope used for visualization of prediction of regular cellular cores influence on energy absorption properties were realized based on ballistics tests area under impact. Figure 1 shows B-scans (XZ, YZ) and C-scan (XY) of the sample A back plate. Position of cross-sections of the 3-D laser ultrasonic data is set by user by red lines. White stripes show positive acoustic pressure recorded by the detector, and black stripes - negative pressure. The thickness of the outgoing edge, measured by the laser ultrasound is $6.91 \mathrm{~mm}$, what is in agreement with measurements by standard gauge. Despite the great sensitivity of laser ultrasound to micro-cracks, no damage of material of internal structure of the outgoing edge was found. This corresponds to the visual observations of a cross-section of the sample A done after cut of the sample.

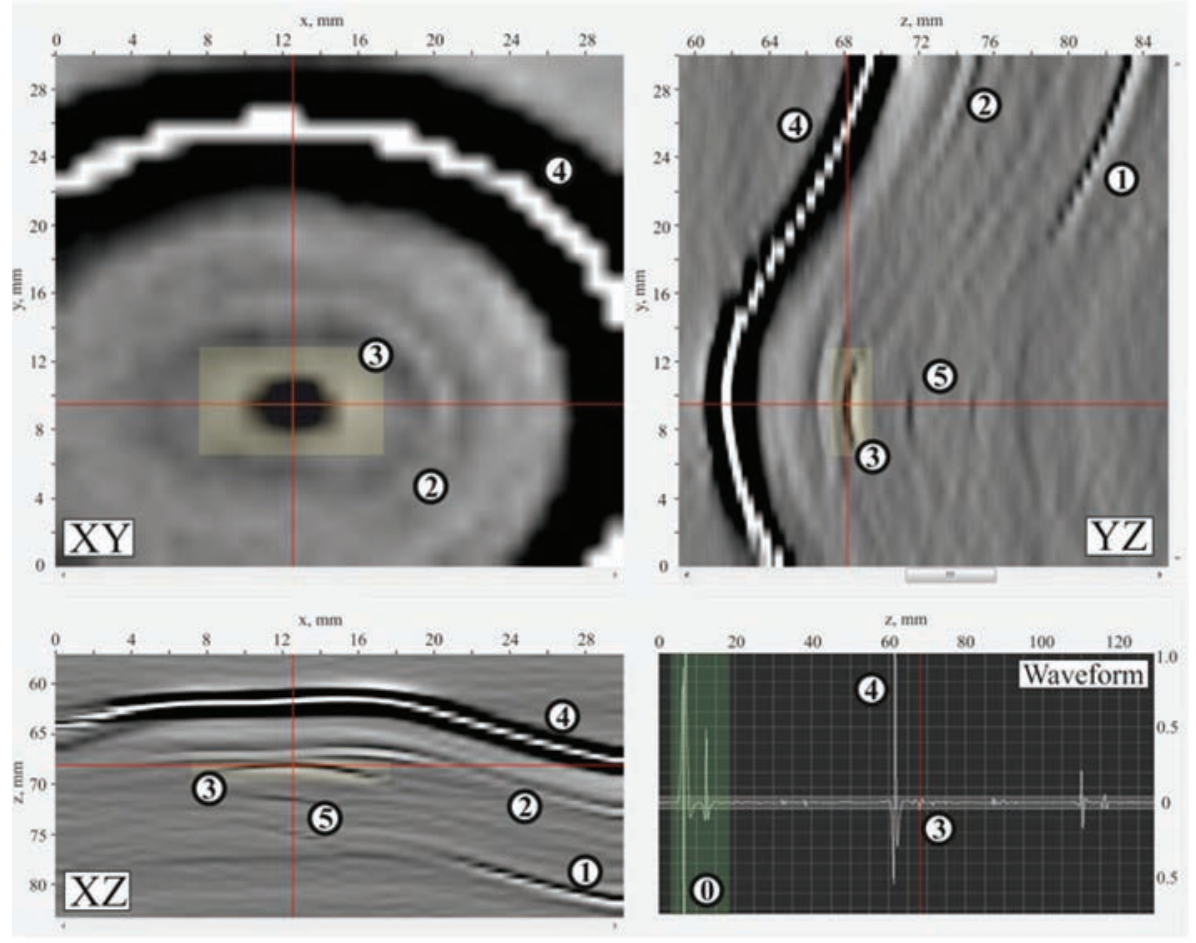

Fig. 2. Laser ultrasonic images of the thick aluminum part of the sample under impact.

0 - probe pulse and its reflection from border of acoustic lens; 1 - bottom of the sample; 2 - reverberation of pulse 4 inside acoustic lens; 3 - reflection of the probe pulse from the outgoing edge; 4 - reflection from the top surface of the sample; 5 - reverberation of pulse 3 inside acoustic lens. Transparent yellow rectangle highlights image of the outgoing edge.

In [73] you can find the description of a non-destructive laser ultrasound internal structure analysis of aluminum joints connected using friction stir welding. In the research, it was taken into account four selected technological parameters groups.

Regarding military applications usage of AA2519 alloy, it is important to determine joint quality without using destructive but also non-destructive methods to analyze obtained material connections directly after the FSW process. The usability growth of FSW technology creates a significant need to determine proper joint quality check method which allows ensuring required connection properties. Ultrasound analysis is useful in testing the material internal quality including in-volume and surface inclusions and defects [26-28].

For the laser amplified ultrasound method verification, the results from the confocal microscope images observations were made (Fig. 3). The T81 sample joint is characterized by the retreating zone - on the right side and advancing side on the left side. Shown in figure 3 joint obtained using the FSW process could be characterized by stir zone recrystallized dynamically (SZ), thermo-mechanically affected zone (TMAZ), heat-affected zone (HAZ) and base material (BM). The T81 samples microstructural analysis did not shown any issues in the FSW-processed joint. Microstructural analysis of samples T41, T82 and T84 revealed some issues to be identified. Mentioned imperfections are shown in Fig. 4. 

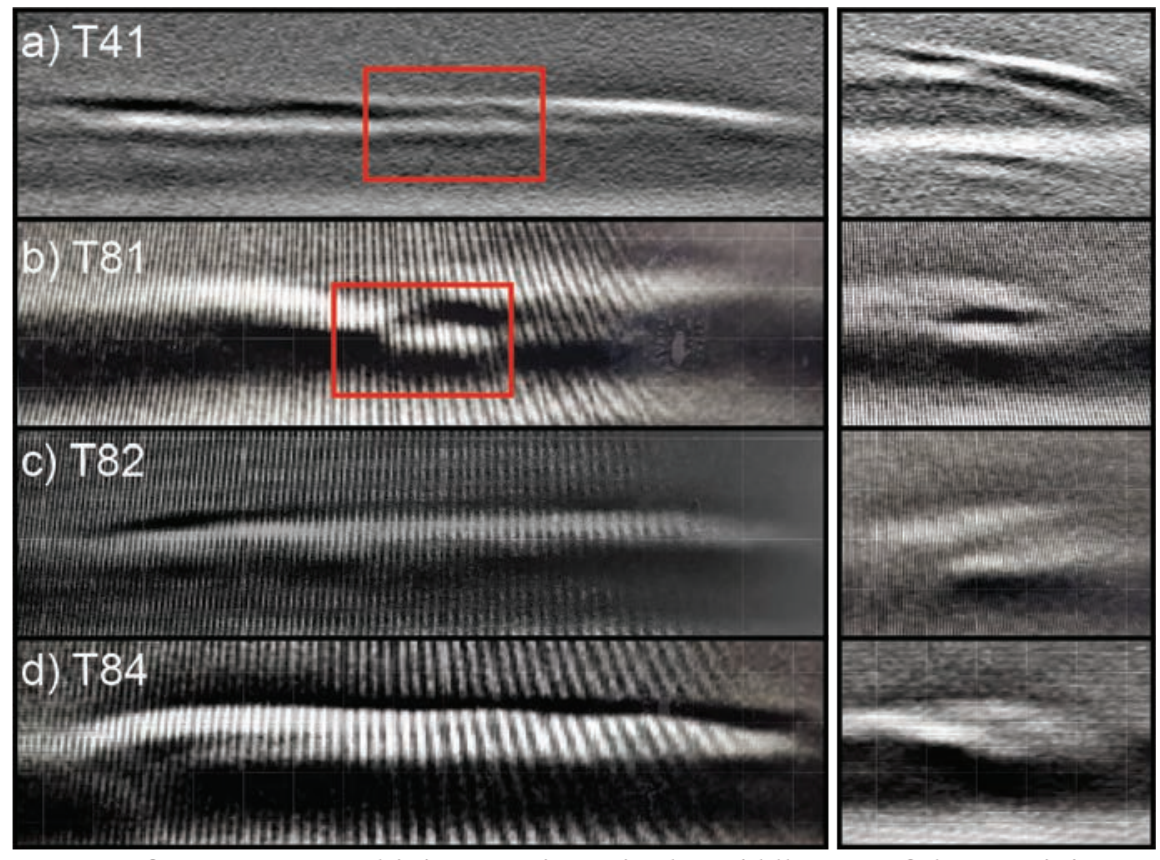

Fig. 3. Internal structure of FSW-processed joints: (a) issue in the middle part of the T41 joint (red box) caused by density change, (b) issue in the central part of the T81 joint (red box) caused by internal voids and density change,

T82 (c) and T84 (d) joint regular stir zone structure.

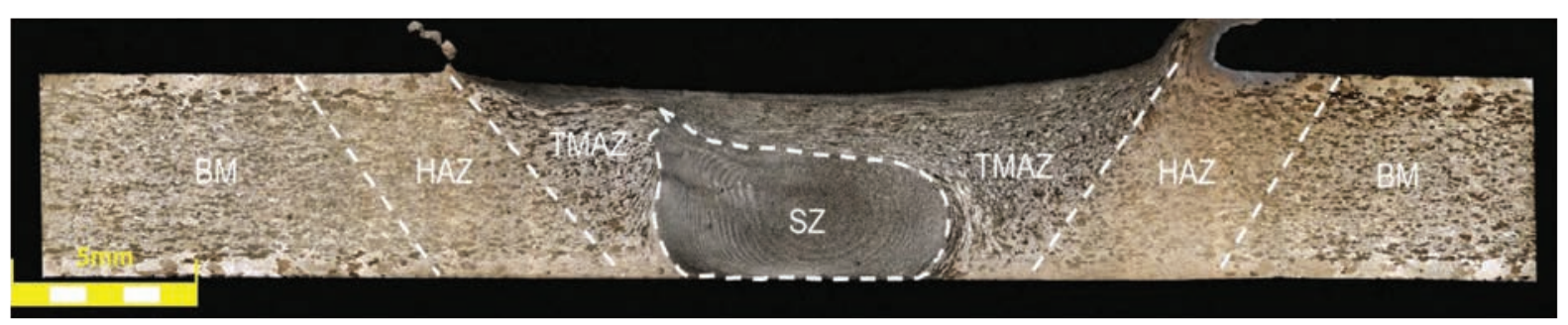

Fig. 4. Macrostructure of the T81 joint.

Selected product using the SLM with evaluated process parameters, experimentally test the product under the conditions reflecting real-world conditions and compare it with a standard product. Implementing numerical methods to the project will give the possibility to analyze the product using different material obtained through experimental acquisition of powder (material) data made using various process parameters. The multi-conditional FEA will be conducted to give the information about product properties and possible modifications. Based on the experimental and FEA results limits and strength of these solutions will be outlined (SWOT analysis). Application of optimization procedure is also planned to define the optimal geometrical parameters of the final product. The authors recently have carried out a series of studies aimed at testing and simulation of various structures manufactures using additive technologies $[60,63,68-72,73]$.

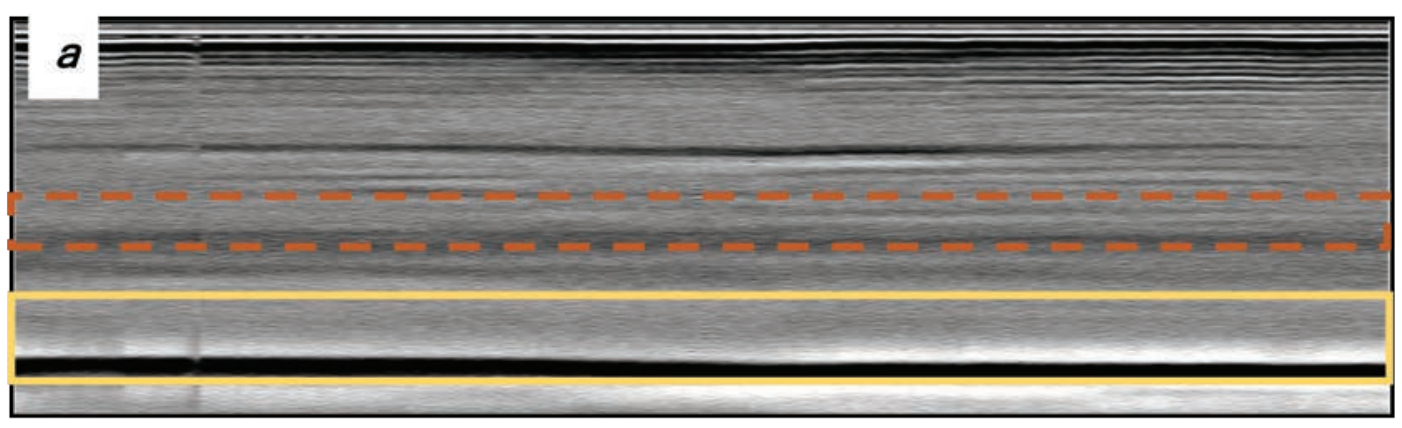




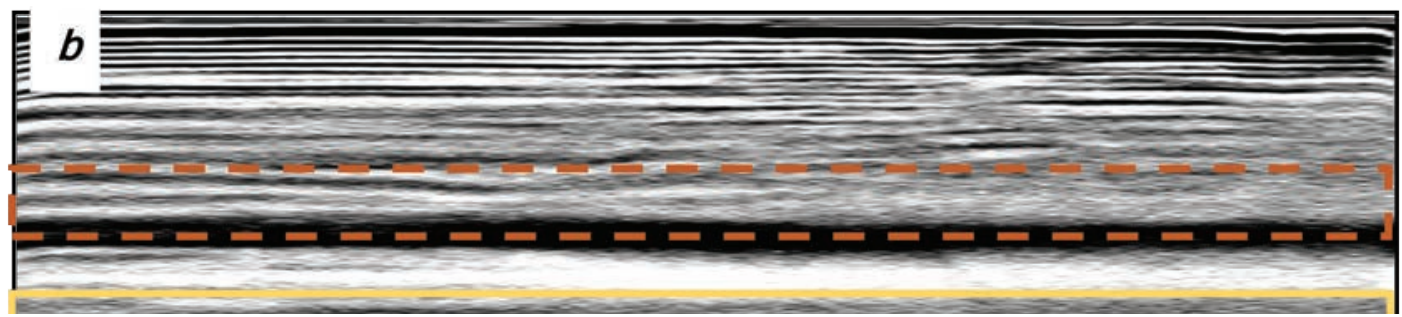

Fig. 5. The internal structure tested with NDT laser-ultrasonic structuroscopy was performed on joints created in the process of multi-material FFF additive manufacturing technology; a) Pleated connection, PLA Though ${ }^{\mathrm{TM}}$, and ABS;

b) Overlap connection, PLA Though ${ }^{\mathrm{TM}}$, and ABS.

In Fig. 5a and 5b, the yellow region indicate its rear side. The unevenness of the displayed backside, which is actually a flat surface, indicates that the binder is heterogeneous and has patches of less dense material. A change in the speed of elastic waves is directly related to a change in elastic properties. The difference from the average value was up to $100 \mathrm{~m} / \mathrm{s}$, which is $3 \%$; with an accuracy of measuring the longitudinal wave velocity of $0.5 \%$. Unevenness can also be due to defects in the internal structure or porosity. 3D model of samples with defective areas designation based on the laser-ultrasonic structuroscopy presented on Fig. 6.

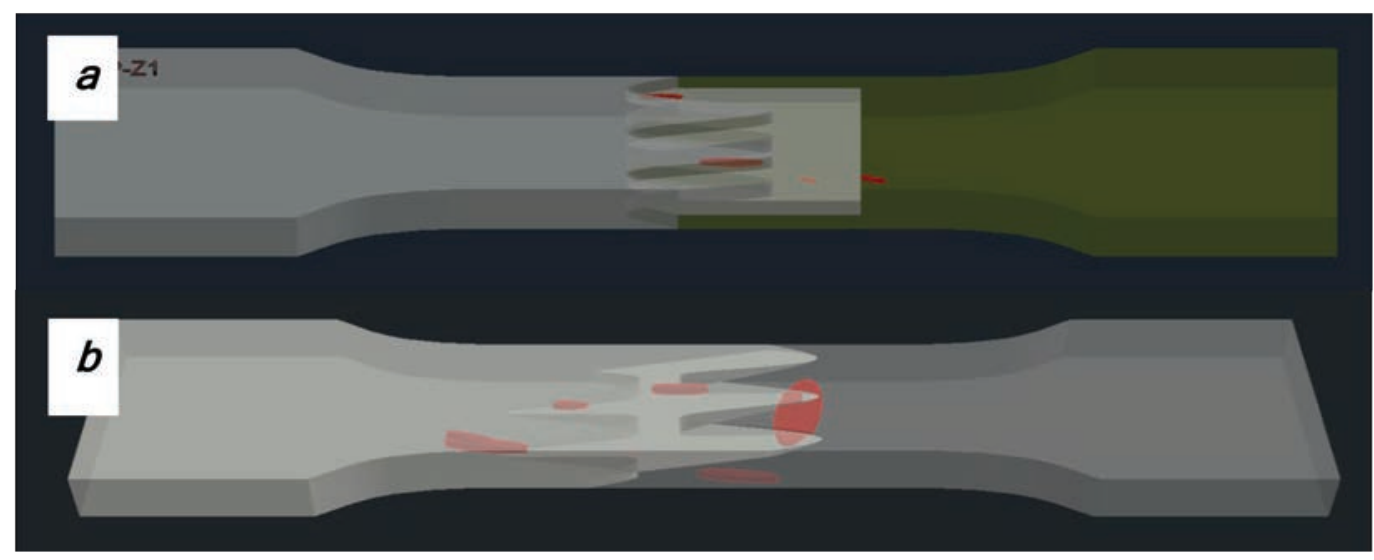

Fig. 6. a). Pleated connection, PLA Though ${ }^{\mathrm{TM}}$, and ABS; b). Overlap connection, PLA Though ${ }^{\mathrm{TM}}$, and ABS.

Fracture analysis of the elements made of PLA and ABS connected using a pleated joint it had been noticed delamination of the joint on the PLA - ABS border and characteristic for the ABS brittle-ductile fracture in the rest of the connection, which was shown in Fig. 7.

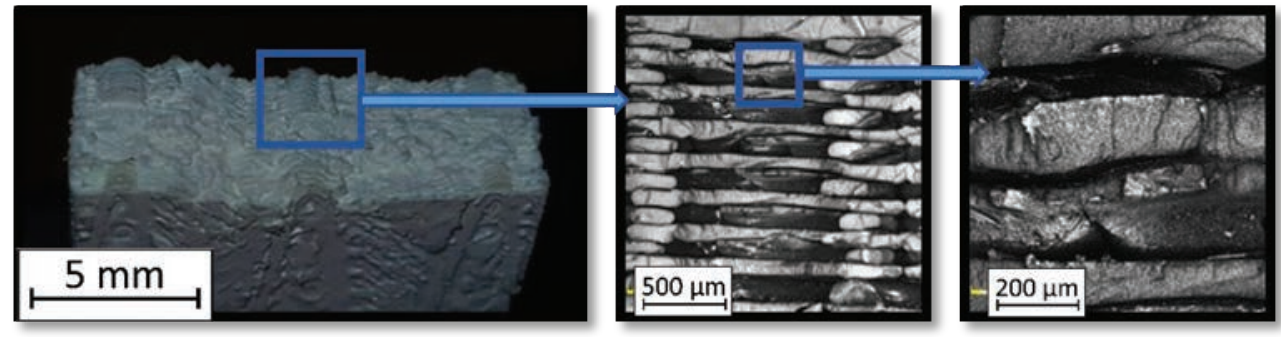

Fig. 7. Fracture images of a pleated joint of PLA-ABS materials.

\section{Conclusions}

To sum up, it's of great importance to start in this begging stages of application of additive manufacturing with development of a series of processes aimed at testing the capabilities of AM technologies and the possibility to deploy them in the form of the standalone facilities and to test this solutions in naval exercise to product different objects in a variety of materials in an open water environment. Especially if we talk about in-situ monitoring system, in these exercises can allow Open Sea Operators to assess new technologies in an isolated and changing maritime 
environment. This system equipped with a thermal imaging system based on high-speed photodiodes and a noncontact laser ultrasonic monitoring system, will enable not only the monitoring of the temperature of the melt pool and the whole object with high resolution to ensure the feedback control of the $3 \mathrm{~d}$ printing process, but also the in-process monitoring of the formation of defects such as pores, microcracks, and laminations.

\section{Acknowledgements}

This research work was supported by the National Ministry of Education of Czech Republic (No. 027/0008465), authors also want to thanks to the Czech Technical University in Prague endowment for support in part of the advanced monitoring of the stability and the technical state of the geological structure of the heritage reservation of Prague.

\section{References}

1. 2nd Fleet, NATO Joint Force Command Norfolk Seek Further Integration of Allied Navies, Megan Eckstein, In: U.S. Naval Institute's, February 5, 2020

2. Yasmin Tadjdeh, Navy beefs up 3D printing efforts with new 'Print the Fleet' program, National Defense Magazine, October 2014

3. Ramon Knulst, 3D printing of marine spare, a case study on the acceptance in the maritime industry. Open University, Nederland, June 2016

4. Additive Manufacturing feasibility study \& technology demonstration. European Defence Agency Strategic Report, June 2018

5. Gibson I., Rosen D., Stucker B. Additive Manufacturing Technologies. Springer New York, 2015.

6. King W. E., Anderson A. T., Ferencz R. M., Hodge N. E., Kamath C., Khairallah, S. A., Rubenchik A. M. Laser powder bed fusion additive manufacturing of metals; physics, computational, and materials challenges, Applied Physics Reviews 2, 2015.

7. Jun H.T., Wai Leong Eugene Wong, Kenneth W.D. An overview of powder granulometry on feedstock and part performance in the selective laser melting process ,Additive Manufacturing, Vol. 18, , pp. 228-255, December, 2017.

8. Bamberg J., Dusel K., Satzger,W. Overview of Additive Manufacturing Activities at MTU Aero Engines, AIP Conference Proceedings, Vol.1650, Isuue 1, pp. 156-163, 2015.

9. Additive manufacturing. General principles. Part 3: main characteristics and corresponding test methods, BS ISO, ISO 17296-3:2014, 2014.

10. Kim H., Moylan S. P.,Garboczi E. J.,Slotwinski J. A. Investigation of pore structure in cobalt chrome additively manufactured parts using X-ray computed tomography and three-dimensional image analysis, Additive Manufacturing, Vol. 17, pp.23-38, 2017.

11. Thijs, L., Verhaeghe, F., Craeghs, T., Humbeeck, J.V., Kruth, J.P. A study of the micro-structural evolution during selective laser melting of Ti-6Al-4V, Acta Mater, Vol. 58, Issue 9, pp.3303-3312, 2010.

12. Clijsters S., Craeghs T., Buls S., Kempen K., Kruth J.P. In situ quality control of the selective laser melting process using a high-speed, real-time melt pool monitoring system, Int. J. Adv. Manuf. Technol, Vol.75, Issue 5, pp.1089-1101,2014.

13. Tammas-Williams S., Zhao H., Leonard F., Derguti F., Todd I., Prangnell P.B. XCT analysis of the influence of melt strategies on defect population in Ti-6Al-4V components manufactured by selective electron beam melting, Mater. Charact, Vol. 102, Issue 4, pp. 47-61,2015.

14. Li R., Liu J., Shi Y., Wang L., Jiang W. Balling behavior of stainless steel and nickel powder during selective laser melting process, Int. J. Adv. Manuf. Technol, Vol.59, Issue 9-12, pp.1025-1035, 2012.

15. Gu D., Shen V. Balling phenomena in direct laser sintering of stainless steel powder: metallurgical mechanisms and control methods, Mater. Des, Vol.30, Issue 8, pp.2903-2910, 2009.

16. Mercelis P., Kruth J.P. Residual stresses in selective laser sintering and selective laser melting, Rapid Prototyp. J., Vol. 12, Issue 5, pp. 254-265, 2006.

17. Zhong Y.C., Il A.L., Seung K.M. Process Monitoring and Inspection Systems in Metal Additive Manufacturing: Status and Applications, International Journal of Precision Engineering and Manufacturing-Green Technology, Vol. 4, Issue 2, pp. 235-245, 2017.

18. Craeghs, S. Clijsters, Kruth J.P., Bechmann F., Ebert M.C. Detection of process failures in layerwise laser melting with optical process monitoring, Phys. Procedia, vol. 39, Issue 1, pp 753-759, 2012.

19. Furumoto T., Alkahari M.R., Ueda T., Aziz M.S.A., Hosokawa A. Monitoring of laser consolidation process of metal powder with high speed video camera, Phys. Procedia, Vol. 39, Issue 1,pp 760-766, 2012. 
20. Furumoto T., Ueda T., Alkahari M.R., Hosokawa A. Investigation of laser consolidation process for metal powder by two-color pyrometer and high-speed video camera, CIRP Ann. Manuf. Technol., Vol. 62, Issue 1, pp. 223-226, 2013.

21. Furumoto T., Ueda T., Kobayashi N., Yassin A., Hosokawa A., Abe S. Study on laser consolidation of metal powder with Yb:fiber laser-evaluation of line consolidation structure, J. Mater. Process. Technol., Vol. 209, Issue 18-19, pp. 5973-5980, 2009.

22. Pavlov M., Doubenskaia M., Smurov I. Pyrometric analysis of thermal processes in SLM technology, Phys. Procedia, Vol. 5, Issue B, pp.523-531, 2010.

23. Doubenskaia M, Pavlov M, Chivel Y. Optical system for on-line monitoring and temperature control in selective laser melting technology, Key Eng. Mater., Vol. 437, pp.458-461, 2010.

24. Islam M, Purtonen T., Piili H., Salminen A., Nyrhilä O. Temperature profile and imaging analysis of laser additive manufacturing of stainless steel, Phys. Procedia, Vol. 41, pp. 835-842, 2013.

25. Krauss H., Eschey C., Zaeh M.F. Thermography for monitoring the selective laser melting process, 23rd International Solid Freeform Fabrication Symposium; Austin, TX, 2012.

26. Rodriguez E., Mireles J., A. C.T., Espalin D., Wicker R. Approximation of absolute surface temperature measurements of powder bed fusion additive manufacturing technology using in situ infrared, Thermography Additive Manufacturing, Vol. 5, pp. 31-39, 2015. Emmanuel Rodriguez, Jorge Mireles, Cesar A. Terrazas, David Espalin, Ryan B. Wicker

27. Khanzadeh M., Chowdhury S., Bian L., Tschopp M.A. A methodology for predicting porosity from thermal imaging of melt pools in additive manufacturing thin wall sections, ASME 2017 12th International Manufacturing Science and Engineering Conference, pp. V002T01A044-V002T01A044, 2017.

28. Mani M., Lane B.M., Donmez M.A., Feng S.C., Moylan S.P. A review on measurement science needs for realtime control of additive manufacturing metal powder bed fusion processes, Int. J. Prod. Res., Vol. 55, Issue 5, pp. 1400-1418, 2017.

29. Khanzadeh M., Tian W., Yadollahi A., Doude H., Bian L. Dual process monitoring of metal-based additive manufacturing using tensor decomposition of thermal image streams, Additive Manufacturing, Vol. 23, Pages 443-456, 2018.

30. Khanzadeh M., Chowdhury S., Marufuzzaman M., Tschopp M.A., Bian L. Porosity prediction: supervisedlearning of thermal history for direct laser deposition, J. Manuf. Syst., Vol. 47, pp. 69-82, 2018.

31. Process Monitoring of Additive Manufacturing by Using Optical Tomography Conference Paper, Conference: Conference: Review of Progress in Quantitative Nondestructive Evaluation, At Boise, Idaho, USA, 2014.

32. Karnati S., Matta N., Sparks T., Liou F. Vision-based process monitoring for laser metal deposition processes, 24th International Solid Freeform Fabrication Sympo-sium, Austin, TX, 2013.

33. Tang L., Landers R.G. Melt pool temperature control for laser metal deposition pro-cesses: part I: online temperature control, J. Manuf. Sci. Eng., Vol. 132, Issue 1, 2010).

34. Song, Mazumder J. Real time Cr measurement using optical emission spectros-copy during direct metal deposition process, ieee sensors j., Vol. 12, Issue 5, pp. 958-964, 2012.

35. Everton S.K., Hirsch M., Stravroulakis P., Leach R.K., Clare A.T. Review of in-situ process monitoring and in-situ metrology for metal additive manufacturing, Materials and Design, Vol.95, pp.431-445, 2016.

36. Tang L., Landers R.G. Melt pool temperature control for laser metal deposition processes: part I: online temperature control, J. Manuf. Sci. Eng., Vol. 132, Issue 1, 2010.

37. Barua S., Liou F., Newkirk J., Sparks T. Vision-based defect detection in laser metal deposition process, Rapid Prototyp. J., Vol. 20, Issue 1, pp. 77-85, 2014.

38. Rodriguez E., Mireles J., Terrazas C. A., Espalin D., Perez M. A. Approximation of Absolute Surface Temperature Measurements of Powder Bed Fusion Additive Manufacturing Technology Using in Situ Infrared Thermography, Additive Manufacturing, Vol. 5, pp. 31-39, 2015.

39. Schomer J. J., Hehr A. J., and Dapino M. J. Characterization of Embedded Fiber Optic Strain Sensors into Metallic Structures Via Ultrasonic Additive Manufacturing, Proc. of SPIE Smart Structures and Materials + Nondestructive Evaluation and Health Monitoring, Paper No. 980320, 2016.

40. Dunbar A. J., Denlinger E. R., Heigel J., and Simpson T. W. Experimental in Situ Distortion and Temperature Measurements during the Laser Powder Bed Fusion Additive Manufacturing Process Part 1: Development of Experimental Method, Additive Manufacturing, 2016. DOI: 10.1016/j.addma.2016.04.007

41. Chua1 Z.Y., Ahn1 I.H., and Moon S.K. Process Monitoring and Inspection Systems in Metal Additive Manufacturing: Status and Applications, International journal of precision engineering and manufacturing-green technology, Vol. 4, Issue 2, pp. 235-245. DOI: 10.1007/s40684-017-0029-7

42. Du Plessis A., le Roux S. G., Booysen G., Els J. Directionality of Cavities and Porosity Formation in Powder- 
Bed Laser Additive Manufacturing of Metal Components Investigated Using X-Ray Tomography, 3D Printing and Additive Manufacturing, Vol. 3, Issue 1, pp. 48-55, 2016.

43. Watkins T, Bilheux H., Ke A., Payzant A., Dehoff R., Duty C.E. Neutron characterization for additive manufacturing, Adv. Mater. Process., Vol. 171, Issue 3, pp. 23-27, 2013.

44. Tremsin A.S., McPhate J.B., Steuwer A., Kockelmann W., Paradowska M., Kelleher A. JF High-resolution strain mapping through time-of-flight neutron transmission diffraction with a microchannel plate neutron counting detector, Vol. 48, Issue 4, pp. 296-305, 2012.

45. Wang F., Mao H., Zhang D., Zhao X, Shen Y. Online study of cracks during laser cladding process based on acoustic emission technique and finite element analysis, Appl. Surf. Sci., Vol. 255, Issue 5, Part 2, pp. 3267-3275, 2008.

46. Wu H., Yu Z., Wang Y. A new approach for online monitoring of additive manufacturing based on acoustic emission ASME 2016 11th International Manufacturing Science and Engineering Conference, paper No. MSEC2016-8551, pp. V003T08A013, 2016. DOI: 10.1115/MSEC2016-8551

47. Shevchik S.A., Kenel C., Leinenbach C., Wasmer K. Acoustic emission for in situ quality monitoring in additive manufacturing using spectral convolutional neural networks Additive Manufacturing, Vol. 21, pp. 598604, May 2018.

48. Rieder H., Dillhöfer A., Spies M., Bamberg J., Hess T. Ultrasonic Online Monitoring of Additive Manufacturing Processes Based on Selective Laser Melting, in AIP Conference Proceedings 1650, edited by D.E. Chimenti and L.J. Bond (American Institute of Physics, Melville, NY), pp. 184-191, 2015.

49. Rieder H., Spies M., Bamberg J., Henkel B. On- and Offline Ultrasonic Characterization of Components Build by SLM Additive Manufacturing, AIP Conference Proceedings 1706, 130002, 2016, doi: 10.1063/1.4940605

50. Edwards R.S., Dutton B., Clough A.R., Rosli M.H. Scanning laser source and scanning laser detection techniques for different surface crack geometries, Review of Prog-ress in Quantitative Nondestructive Evaluation; Burlington, VT: AIP Conference Proceedings, pp. 251-258, 2012.

51. Cerniglia D., Scafidi M., Pantano A., Lopatka R. Laser ultrasonic technique for laser powder deposition inspection, Laser, Vol. 6, Issue 150, p. 13, 2013.

52. Dong F., Wang X., Yang Q., Yin A., Xu X. Directional dependence of aluminum grain size measurement by laser-ultrasonic technique. Mater. Charact, Vol. 129, pp. 114-120, 2017

53. Ruipeng G., Haitao W., Jianyan Z. Non-contact detection of low carbon steel using laser generated ultrasound at high tempera-ture. Opt. - Int. J. Light Electron Opt, Vol. 136, 536-542, 2017.

54. Mi B, Ume C., Real-time weld penetration depth monitoring with laser ultrasonic sensing system. J. Manuf. Sci. Eng., Vol. 128, Issue 1, p. 280, 2006.

55. Millon C., Vanhoye A., Obaton A., Penot J. Development of laser ultrasonics inspection for online monitoring of additive manufacturing Welding in the World, Vol. 62, pp. 653-661, 2018.https://doi.org/10.1007/s40194-0180567-9

56. Dubrov A.V., MirzadeF.Kh, Dubrov V.D. Mathematical modeling of thermal behavior for additive manufacturing with metal powder injection (2017)Procedia Engineering, 201, p. 478-488

57. Dubrov A.V., MirzadeF.Kh, Dubrov V.D., PanchenkoV.Ya. Heat Transfer and Thermocapillary Convection during the Laser Deposition of Metal Powders Implemented in Additive Technologies (2018) Surface Investigation X-Ray, Synchrotron and Neutron Techniques, 12(1), p. 54-63.

58. Kravcov A., Platek P., Pospíchal V., Koperski W. Internal structure research of 3D printed cellular structures by laser-ultrasonic structuroscopy, In: 2019 International Conference on Military Technologies (ICMT). 2019. p. 92-99. ISBN 978-1-7281-4594-5

59. Kucewicz M., Baranowski P.,Małachowski J., Poplawski A., Platek P. Modelling, and characterization of 3D printed cellular structures, Mater. Des. 142 (2018). doi:10.1016/j.matdes.2018.01.028.

60. Dziewit P., Platek P., Janiszewski J., Sarzyński M., Grązka M., Paszkowski R. Mechanical Response of Additive Manufactured Regular Cellular Structures in Quasi-Static Loading Conditions - Part I Experimental Investigations, in: S. Gomes, S.A. Meguid (Eds.), Proc. 7th Int. Conf. Mech. Mater. Des., Albufeira, 2017: pp. 1061-1074.

61. Ozdemir Z., Tyas A., Goodall R., Askes H., Energy absorption in lattice structures in dynamics: Nonlinear FE simulations, Int. J. Impact Eng. 102 (2017) 1-15. doi:10.1016/j.ijimpeng.2016.11.016.

62. Zhang X., An L., Ding H. Dynamic crushing behavior and energy absorption of honeycombs with density gradient, J. Sandw. Struct. Mater. 16 (2014) 125-147. doi:10.1177/1099636213509099.

63. Zhang Y., Xu X., Wang J., Chen T., Wang C.H. Crushing analysis for novel bio-inspired hierarchical circular structures subjected to axial load, Int. J. Mech. Sci. 140 (2018) 407-431. doi:10.1016/j.ijmecsci.2018.03.015.

64. Mayer P., Pyka D., Jamroziak K., Pach J., Bocian M. Experimental and Numerical Studies on Ballistic 
Laminates on the Polyethylene and Polypropylene Matrix, J. Mech. (2017) 1-11. doi:10.1017/jmech.2017.103.

65. Kedzierski P., Gieleta R., Morka A., Niezgoda T., Surma Z. Experimental study of hybrid soft ballistic structures, Compos. Struct. 153 (2016) 204-211. doi:10.1016/j.compstruct.2016.06.006.

66. Mazurkiewicz L., Malachowski J., Baranowski P. Blast loading influence on load carrying capacity of I-column, Eng. Struct. 104 (2015) 107-115. doi:10.1016/j.engstruct.2015.09.025.

67. Baranowski P., Małachowski J., Platek P., Szafrańska A. LENS Ti-6Al-4V alloy material properties determination for LS-Dyna package, AIP Conference Proceedings, Vol. 2078, paper no.20058, 2019, doi: $10.1063 / 1.5092061$

68. Płatek P., Baranowski P., Cieplak K., Sarzyński M., Sienkiewicz J., Janiszewski J., Małachowski J. Investigation on deformation process of cellular structures with gradient topology manufactured additively, AIP Conference Proceedings, Vol. 2078, paper no. 20108, 2019, doi: 10.1063/1.5092111

69. Szafrańska A., Antolak-Dudka A., Baranowski P., Bogusz P., Zasada D., Małachowski J., Czujko T. Identification of mechanical properties for titanium alloy Ti-6Al-4V produced using LENS technology, Materials, Vol. 16, No. 6, paper no. 886, 2019, doi: 10.3390/ma12060886

70. Antolak-Dudka A., Platek P., Durejko T., Baranowski P., Małachowski J., Sarzyński M., Czujko T. Static and dynamic loading behavior of Ti6Al4V honeycomb structures manufactured by Laser Engineered Net Shaping (LENSTM) technology, Materials, Vol. 12, No. 8, paper no. 1225, 2019, doi: 10.3390/ma12081225

71. Baranowski P., Platek P., Antolak-Dudka A., Sarzyński M., Kucewicz M., Durejko T., Małachowski J., Janiszewski J. Czujko T., Deformation of honeycomb cellular structures manufactured with Laser Engineered Net Shaping (LENS) technology under quasi-static loading: Experimental testing and simulation, Additive Manufacturing, Vol. 25, pp. 307-316, 2019, doi: 10.1016/j.addma.2018.11.018

72. Kravcov, A., Kosturek, R., Śnieżek, L., Kluczyński, J., Franek O., Morozov, N., Maciejewski, P. The influence of friction stir welded process parameters of aa2519-t62 on joint quality defined by non-destructive laser amplified ultrasonic method and by microstructure analysis, Acta Polytechnica, ISSN 1210-2709

73. Kravcov, A.; Kluczynski, J.; Śnieżek, L.; Svoboda, P.; Grzelak, K.; Morozov, N.; Franek, O.; Kubeček, P. et al. The examination of restrained joints created in the process of multi-material FFF additive manufacturing technology, Materials. 2020, 13(4), 903-918. ISSN 1996-1944. 